Article

\title{
Are Non-Perennial Rivers Considered as Valuable and Worthy of Conservation as Perennial Rivers?
}

\author{
Pablo Rodríguez-Lozano ${ }^{1,2}{ }^{*} * \mathbb{D}$, Cleo Woelfle-Erskine ${ }^{3}$, Michael T. Bogan ${ }^{4}$ and \\ Stephanie M. Carlson ${ }^{1}$ (D) \\ 1 Department of Environmental Science, Policy, and Management, University of California at Berkeley, \\ Berkeley, CA 94720, USA; smcarlson@berkeley.edu \\ 2 Department of Geography, University of the Balearic Islands, 07122 Palma, Spain \\ 3 School of Marine and Environmental Affairs, University of Washington, Seattle, WA 98195, USA; \\ cleowe@uw.edu \\ 4 School of Natural Resources and the Environment, University of Arizona, Tucson, AZ 85721, USA; \\ mbogan@arizona.edu \\ * Correspondence: pablo.rodriguez@uib.es
}

Received: 22 June 2020; Accepted: 15 July 2020; Published: 17 July 2020

\begin{abstract}
Non-perennial rivers, watercourses that cease to flow at some point in time and space, are widespread globally but often lack effective protections. Although it is thought that these ecosystems are undervalued by society, empirical studies exploring people's perceptions of non-perennial rivers are uncommon. We carried out an image-based survey at three U.S. universities to measure students' perception of riverscapes according to seven characteristics: aesthetics, naturalness, habitat for biodiversity, habitat for fish, need of human intervention, importance for human well-being, and conservation value. Our results showed that non-perennial rivers are generally considered less valuable and worthy of conservation than their perennial counterparts. Furthermore, several factors influenced peoples' perception of non-perennial rivers, including where they live, their educational history, how often they visit rivers, their leisure activities, and whether they live close to a river. Our findings suggested the need to improve people's perceptions of non-perennial rivers as a step toward increased protection for these ecosystems. This current challenge demands combined actions by researchers from diverse disciplines and professionals working from different perspectives, including policymakers and educators.
\end{abstract}

Keywords: conservation; dry riverbeds; education for sustainability; environmental perception; freshwater ecosystems; human dimensions; isolated pools; non-perennial rivers; socio-ecological systems; transdisciplinary research

\section{Introduction}

Non-perennial rivers, those watercourses that cease to flow at some point in time and space, are common in many parts of the world. Their length at the global scale is increasing as perennial rivers lose flow due to climate change and human diversions of water [1,2]. Non-perennial rivers comprise $59 \%$ of the length of river networks in the USA and over $90 \%$ in many arid regions [3]. Despite our deepening knowledge about the ecology and hydrology of non-perennial rivers $[4,5]$, current paradigms in river science and management are largely founded on studies of perennial rivers. The relative lack of scientific attention on non-perennial rivers may lead the public to devalue them and underestimate their ecological importance; such lack of public concern for non-perennial rivers is significant given challenges to their legal and regulatory status worldwide [6-8]. The removal of many non-perennial rivers from protection under the USA Clean Water Act is one recent example of such threats. 
Several scientific publications about non-perennial rivers suggest that these ecosystems are undervalued by society [9-11], but empirical research focusing on people's perceptions of non-perennial rivers is rare [12,13]. Armstrong et al. [12] showed that riparian landowners with a perennial river adjacent to their property valued the river more and were more concerned about its water quality compared to landowners with properties near non-perennial rivers. Similarly, a study exploring human-nature relationships in Mediterranean streams [14] found that some landholders undervalued non-perennial rivers. On the other hand, societies in arid and semi-arid regions can have strong affinities with non-perennial rivers, and these ecosystems are part of their culture as a source of food and water. For example, people in Botswana dig in dry riverbeds to find and harvest dormant catfish that pass the dry season aestivating in the riverbed [9]. A recent study [13] showed that undergraduate students from the United Kingdom, USA, and Australia have, in general, positive attitudes toward non-perennial rivers. From a broader perspective, Herzog [15] concluded that people usually find landscapes containing water more aesthetically pleasing compared to those without water and, within waterscapes, people tend to prefer waterfalls and running water to stagnant water.

Understanding the social value people place on non-perennial rivers could help improve management actions aimed at their conservation, enhance communication about these systems to stakeholders, and increase public awareness of these ecosystems. To this end, we designed a study to explore the social perception of non-perennial rivers. Specifically, we aimed to compare how people perceive riverscapes of running rivers, isolated pools, and dry riverbeds. We hypothesized that people would perceive riverscapes more positively when they contained water (running rivers and isolated pools) compared to dry riverbeds. We also hypothesized that the perception of non-perennial rivers could differ by geography and educational history. Specifically, we predicted that climate context would drive the social perception of non-perennial rivers and that perceptions would vary depending on people's previous training in ecology and related fields. To test our hypotheses, we carried out an image-based online survey of undergraduate and graduate students at three USA universities located in different climatic contexts: University of Washington (Oceanic climate), University of California at Berkeley (Mediterranean climate), and University of Arizona (desert climate).

\section{Methods}

We carried out an image-based online survey to measure people's perception of digital photographs from a variety of rivers. Nine photos of rivers were used (see Figure 1 and Figure S1 in Supplementary Material): three depicting running rivers, three showing isolated pools, and three others showing dry riverbeds. The chosen photos were otherwise similar (i.e., similar river size, no human impact, panoramic view, absence of large woody debris, and presence of vegetation along the river).

Written informed consent was obtained at the beginning of the online survey. Then, observers were invited to score each of the nine pictures according to seven characteristics: aesthetics, naturalness, habitat for biodiversity, habitat for fish, need for improvement, importance for human well-being, and conservation value. Respondents rated each metric for each picture on a visual analog scale (VAS) by moving a slider along a line segment with two endpoints (e.g., ranging from "not natural" to "completely natural" for naturalness). We used a 101-point VAS with no numerical feedback, i.e., the position of the slider (0 to 100) was not displayed, and the VAS had no numeric labels, only the two endpoints with text labels. This methodology allows freedom of response and avoids other methodological bias such as response rounding $[16,17]$. The order of presentation of the nine images was randomized. Moreover, each observer provided sociodemographic information regarding 10 factors: age, gender, race and ethnicity, university, population size of their city or town, whether there was a river located close to their residence, frequency of river visitation, river visitation as part of a job or school, leisure activities near rivers, and previous training in related fields (i.e., university courses taken previously by the student). The survey was conducted using Qualtrics software. 

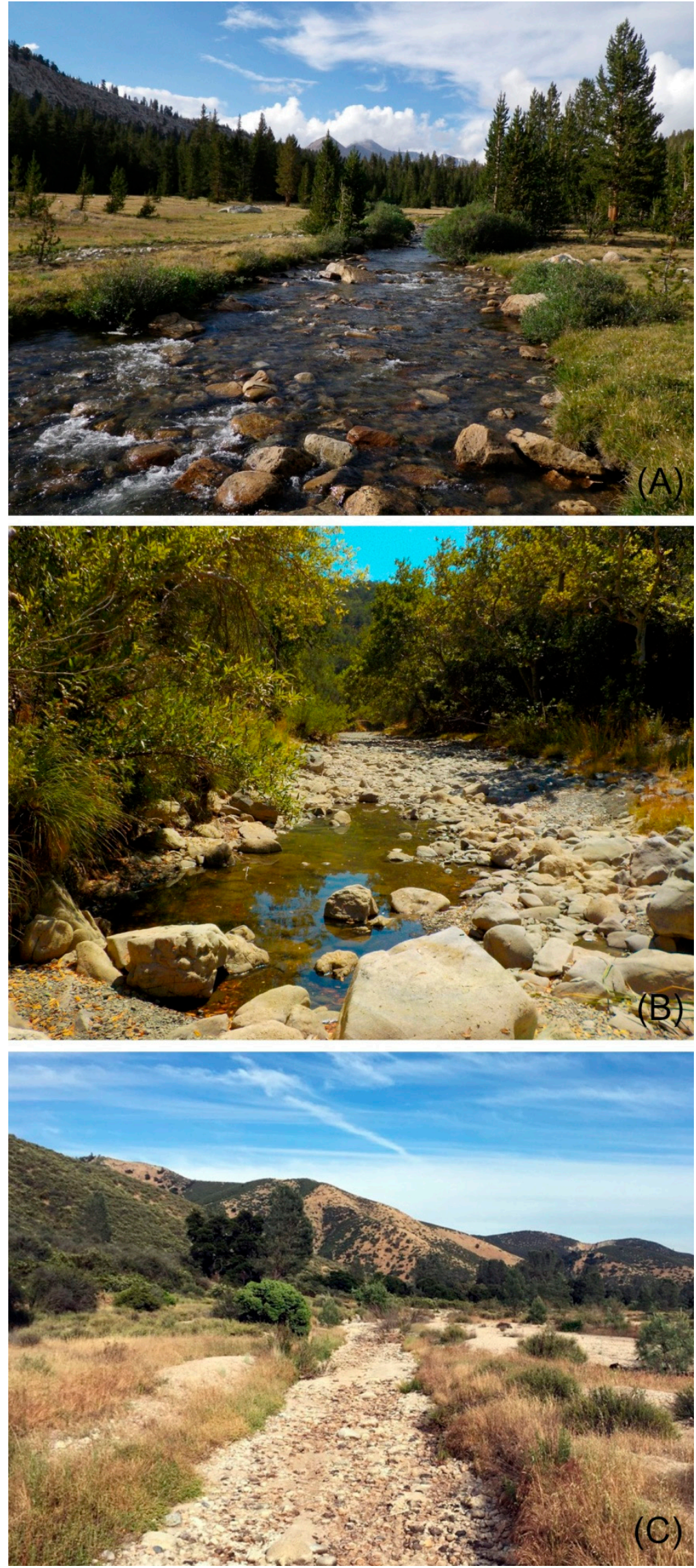

Figure 1. Examples of the photographs used in the survey: running river (A) (photo by MTB), isolated pool (B) (photo by PR-L), and dry riverbed (C) (photo by MTB). See Figure S1 for all photographs. 
Undergraduate and graduate students at the three universities (University of Washington (UW), University of California at Berkeley (UCB), and University of Arizona (UA)) were invited to participate in the research study through their university e-mail accounts. An email was sent to university professors asking them to forward the invitation to the students in their classes. About 70 professors were contacted in each university, with a goal of covering all disciplines and colleges, reaching professors teaching basic courses with high enrollment, and reaching courses related to water in a broad sense. Additionally, we contacted some undergraduate and graduate advisors asking them to forward the survey to the students enrolled in their programs. The dissemination of the survey was carried out at the start of the 2018 academic year, and the survey was active from September to December 2018.

A total of 872 complete responses were collected. Of these, 791 responses were used for analyses. We removed respondents from the sample who did not indicate their institution (i.e., UW, UCB, or UA). We also removed responses from respondents who answered $<75 \%$ of the image-based questions (i.e., item nonresponse) [18].

Spearman's rank correlation coefficients were computed from scores of aesthetics, naturalness, habitat for biodiversity, habitat for fish, need for improvement, human well-being, and worthy of conservation to measure the strength of the associations between these seven quantitative variables.

For each of the seven variables, we constructed an individual linear mixed-effects model (LMM) with flow status (running water, isolated pool, or dry riverbed) and sociodemographic variables (see Table S1 in Supplementary Material) set as fixed effects, and image ID and respondent ID set as random effects. Model selection was done in a backward stepwise manner using Akaike's information criterion (AIC) and likelihood ratio tests to achieve the minimum adequate model for each variable. Both random effects, i.e., respondent ID and image ID, were included in every model. Selected models were validated by visually checking their residuals for normality and homoscedasticity [19]. To test for multicollinearity, the variance inflation factors (VIFs) of all predictors in the final models were calculated ("vif" function, "car" package). Adjusted generalized VIFs $\left(\operatorname{GVIF}^{\wedge}(1 /(2 \times \mathrm{df}))\right.$, where $\mathrm{df}$ is degrees of freedom) were used because they are comparable among predictors [20]. Adjusted GVIFs never exceeded 2.0 (which equals to an ordinary VIF of 4 for one-coefficient variables), confirming that multicollinearity levels were appropriate for analysis. We also checked that all final models were not singular ("isSingular" function, "lm4" package). The proportion of explained variance in the selected models $\left(\mathrm{R}^{2}\right)$ was calculated using the "r.squaredGLMM" function ("MuMIn" package), which calculates both the conditional coefficient of determination $R^{2} c$ (it represents the variance explained by the fixed effects) and the marginal coefficient of determination $R^{2} \mathrm{~m}$ (it represents the variance explained by the entire model, including both fixed and random effects) [21]. To test for differences among levels within fixed effects, we performed post-hoc Tukey pairwise comparisons on the results of the LMMs. All statistical analyses were performed using the R statistical software version 3.4.1 (R Foundation for Statistical Computing, Vienna, Austria) (packages "Ime4", "lmerTest", "car", and "MuMIn"), with the significance level set at $\alpha<0.05$ for all tests.

\section{Results}

Of the 791 responses, 177 (22\%) were students from the University of Washington, 456 (58\%) from the University of California, Berkeley, and $158(20 \%)$ from the University of Arizona. Most respondents were $<25$ years old $(71 \%)$ and half $(50 \%)$ reported living near a river most of their lives. The most common leisure activities along rivers reported by respondents included hiking $(86 \%)$, relaxing/resting $(69 \%)$, and picnicking, camping, and other social activities (52\%). The three most common courses that respondents reported having taken were general Environmental Studies $(46 \%)$, general Ecology $(38 \%)$, and a course in Climate Change (30\%) (see Table S1 for a complete respondents' characterization).

Correlation analysis showed that the two strongest-correlated variables were habitat for biodiversity and habitat for fish (Spearman's rho $=0.681, p<0.001$ ). Need of improvement was best correlated with aesthetics (Spearman's rho $=-0.581, p<0.001$ ) and with habitat for fish (Spearman's rho $=-0.483, p<0.001$ ) 
and biodiversity (Spearman's rho $=-0.458, p<0.001$ ). Worthy of conservation was best correlated with human well-being (Spearman's rho $=0.507, p<0.001$ ) and aesthetics (Spearman's rho $=0.489$ ). Human well-being was weakly correlated with naturalness (Spearman's rho $=0.212, p<0.001$ ) but more strongly correlated with aesthetics (Spearman's rho $=0.431$ ), habitat for biodiversity (Spearman's rho $=0.425$, $p<0.001$ ), and fish (Spearman's rho $=0.405, p<0.001$ ) (see Table S2 for all pairwise correlations in Supplementary Material).

The explanatory variables, i.e., flow status and sociodemographic factors, explained a large part of the variability in the riverscapes' perception among respondents (see Table S3 in Supplementary Material); the amount of variance explained by final LMMs was highest for habitat for fish $\left(R^{2} m=0.5446\right.$; $\left.R^{2} c=0.668\right)$ and lowest for naturalness $\left(R^{2} m=0.0935 ; R^{2} c=0.315\right)$. LMMs showed that flow status (i.e., flowing, stagnant, dry) had a statistically significant effect on respondents' perception of the seven tested variables and was always the factor responsible for the greatest percentage of variance explained (range: $38 \%$ for need of improvement to $12 \%$ for conservation value, see Table S3). Post-hoc Tukey tests confirmed that respondents perceived more positively images depicting rivers with flow than images showing isolated pools and dry riverbeds for the seven characteristics measured (Figure 2, Table S3). Additionally, images showing isolated pools were rated more positively than images of dry riverbeds for three characteristics (habitat for biodiversity, habitat for fish, and conservation value), while there were no differences between the perception of isolated pools and dry riverbeds for the other four response variables (Figure 2, Table S3).

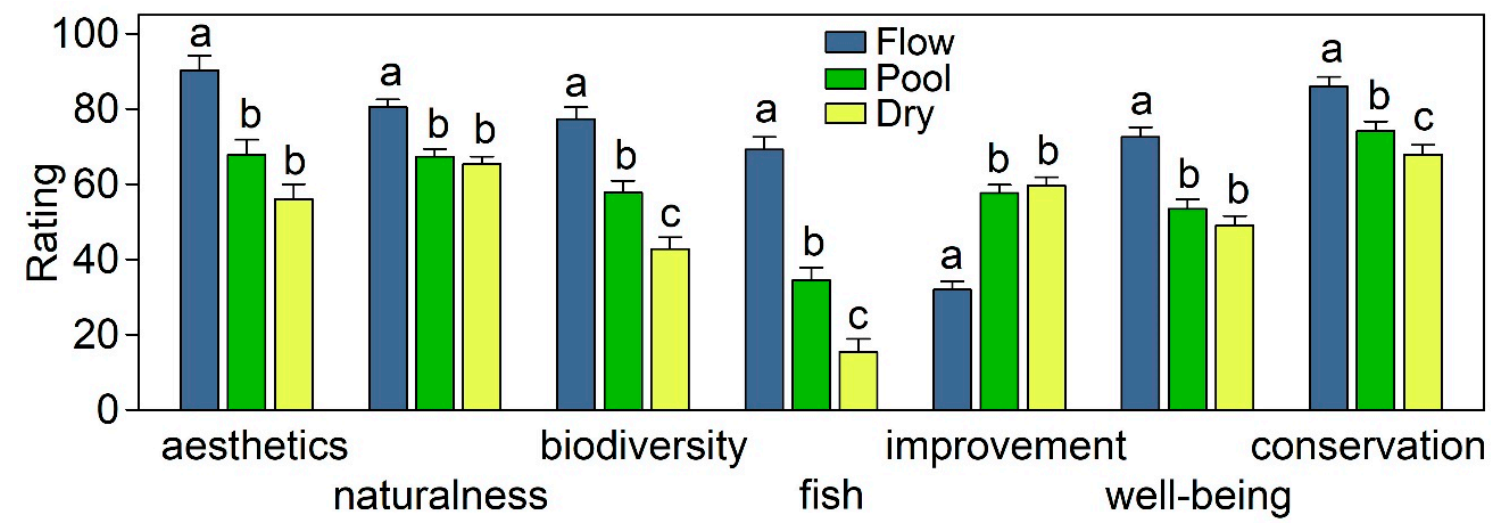

Figure 2. Respondents' perception of images of flowing rivers (blue), isolated pools (green), and dry riverbeds (yellow) for the seven characteristics evaluated: aesthetics, naturalness, habitat for biodiversity, habitat for fish, need of improvement, human well-being, and conservation value. Bars indicate the mean (+ 1 SE) respondents' rating using visual analog scales. Different letters indicate statistically significant differences (Tukey's post-hoc tests, $p<0.05$ ). See Table S4 for full statistics.

In addition to flow status, several sociodemographic factors influenced respondents' perceptions of the river images (see Table S4). Perceptions of aesthetics, naturalness, habitat for biodiversity, need for improvement, and conservation value differed among locations, and the interaction between flow status and location was statistically significant for all five of these characteristics. Perception of images showing running rivers did not differ among locations, but images of isolated pools and dry riverbeds received higher scores from UW students than from students at UCB and UA for aesthetics, naturalness, habitat for biodiversity, and conservation value. UA students also expressed that dry riverbeds were more in need of human intervention than UW students.

University education also had significant effects on people's perceptions of rivers. Students who completed a general course in Ecology gave higher scores to dry riverbeds for naturalness, and to both isolated pools and dry riverbeds for habitat for fish, compared to those who had not done so (Figure 3A). Respondents who took a course on Freshwater Ecology perceived all images as being more natural and expressed that both isolated pools and dry riverbeds were less in need of improvement than those who 
did not take this specific course. Respondents who had studied Environmental Philosophy or Ethics considered isolated pools more beautiful that those who had not (Figure 3B). Finally, respondents who finished a general course on Environmental Studies considered isolated pools more important for human well-being and both isolated pools and dry riverbeds more worthy of conservation than those who did not take such a course (Figure 3C,D).
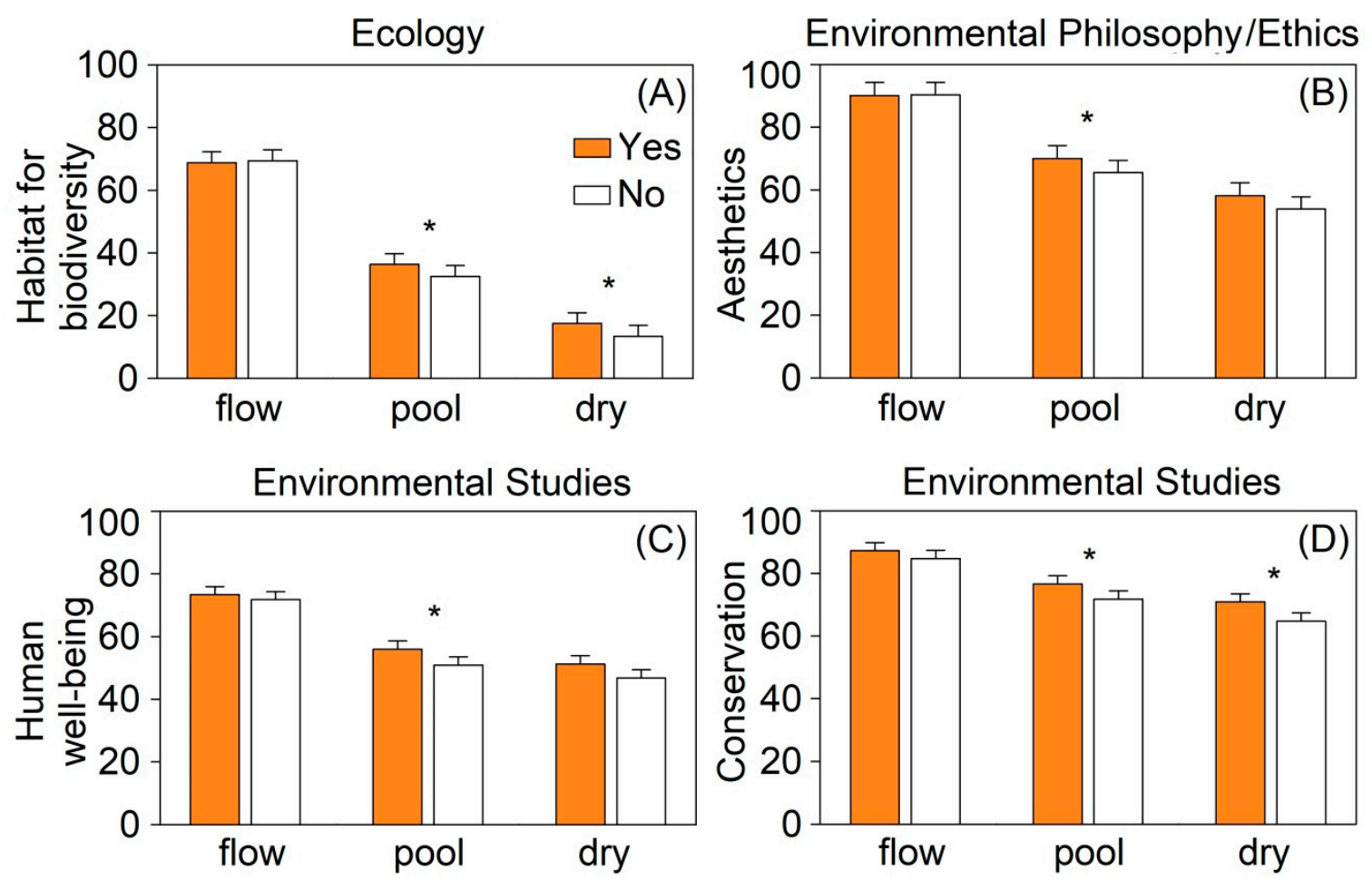

Figure 3. Effects of university education on the perception of images of flowing rivers ("flow"), isolated pools ("pool"), and dry riverbeds ("dry"). Effects of completing a general course in Ecology on the perception regarding habitat for biodiversity (A), a course in Environmental Philosophy or Ethics on the perception regarding aesthetics (B), a course in Environmental Studies on the perception regarding human well-being (C), and conservation value (D). Orange bars indicate responses from students who completed the course, while white bars indicate the opposite. Minimum $N=404$ (for responses regarding aesthetics' perception of images of dry riverbeds from students who completed a course in Environmental Philosophy/Ethics). Bars indicate the mean (+1 SE) respondents' rating using visual analog scales. * indicates statistically significant differences (Tukey's post-hoc tests, $p<0.05$ ). See Table S4 for full statistics.

Respondents who lived most of their lives close to a river gave higher scores to isolated pools and dry riverbeds for habitat for biodiversity and fish and considered dry riverbeds more worthy of conservation than those who did not live close to a river (Figure 4A,B). River perception also varied with leisure activities. For instance, respondents that visited rivers to observe fauna (e.g., birdwatching) perceived isolated pools and dry riverbeds as more beautiful than those who did not. Similarly, those who visited rivers to hike considered dry riverbeds more beautiful and all rivers less in need of human intervention than respondents that did not visit rivers to hike (Figure 4C,D). Respondents who visited rivers more frequently showed a more positive perception of riverscapes, specifically regarding aesthetics, habitat for biodiversity, human well-being, and conservation value (Figure 5). Frequency of river visitation had a greater impact on the perception of both isolated pools and dry riverbeds than on the perception of flowing rivers. Indeed, the perception of flowing rivers regarding aesthetics and habitat for biodiversity did not increase with visitation frequency (Figure 5A,B). For instance, respondents who visited rivers more than 20 times a year perceived the conservation value of dry 
riverbeds to be $31 \%$ higher than those who visited rivers less than once a year, while their perception of the conservation value of flowing rivers was only $6 \%$ higher (Figure 5D).
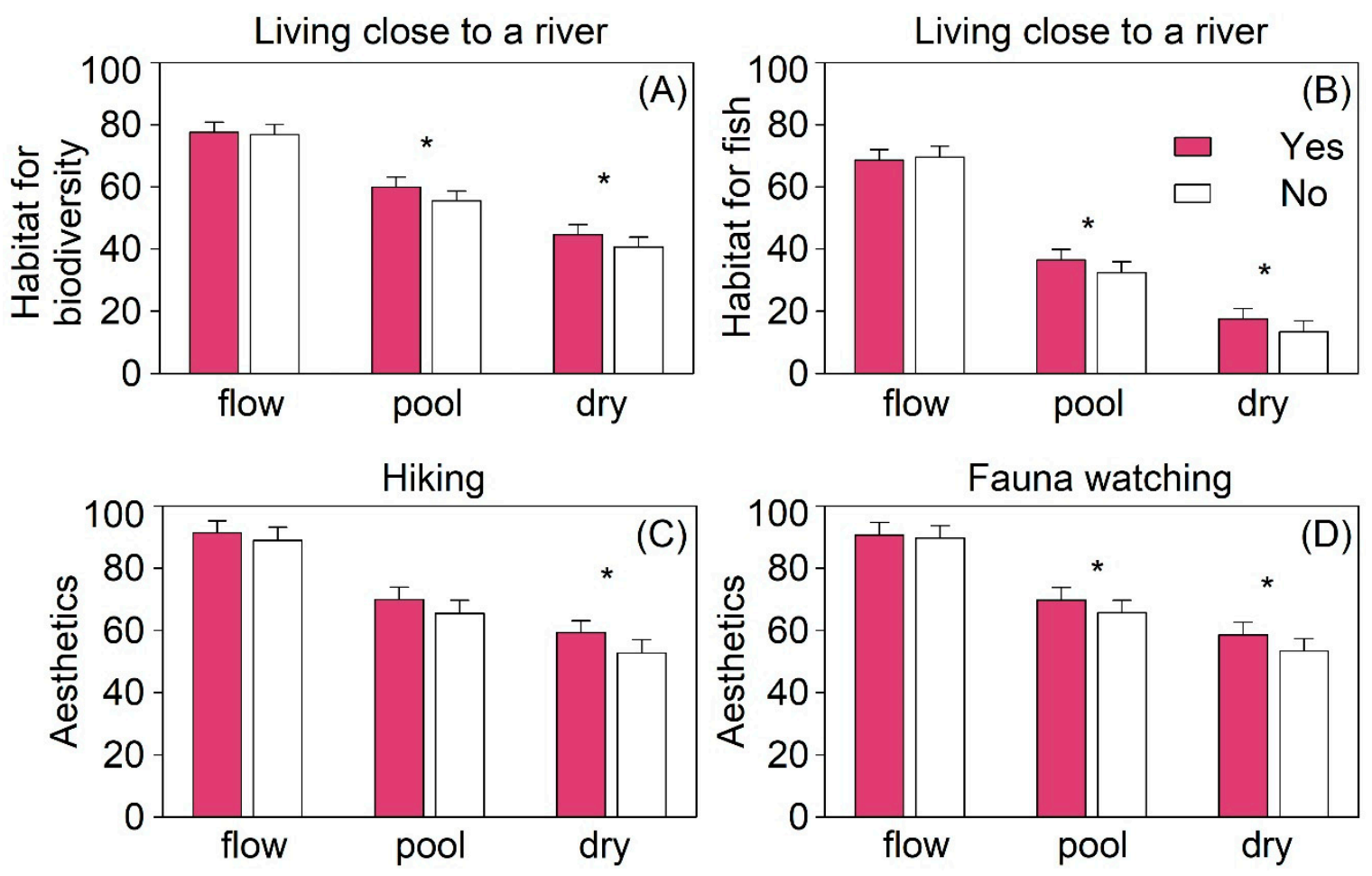

Figure 4. Effects of living close to a river $(\mathbf{A}, \mathbf{B})$ and practicing leisure activities, specifically hiking (C) and fauna watching (D), on the perception of images of flowing rivers ("flow"), isolated pools ("pool"), and dry riverbeds ("dry") regarding habitat for biodiversity (A), habitat for fish (B) and aesthetics (C,D). Pink bars indicate responses of students who live close to a river or practice the leisure activities, while white bars indicate the opposite. Minimum $N=285$ (for responses regarding aesthetics' perception of images of dry riverbeds from students who did not practice hiking). Bars indicate the mean (+ $1 \mathrm{SE})$ respondents' rating using visual analog scales. ${ }^{*}$ indicates statistically significant differences (Tukey's post-hoc tests, $p<0.05)$. See Table $\mathrm{S} 4$ for full statistics.

Respondents' age had a significant effect on the perception of riverscapes regarding aesthetics, habitat for biodiversity, need for improvement, human well-being, and conservation value (see Table S4 in Supplementary Material). Similar to the pattern found for the frequency of river visitation, relatively older students generally expressed a more positive perception of non-perennial rivers when compared to relatively younger students, while age effects on the perception of perennial rivers were low or negligible. For example, students $>29$ years old perceived the conservation values of flowing rivers, isolated pools, and dry river beds to be $3 \%, 11 \%$, and $12 \%$ higher, respectively, than did students who were $<25$ years old. Moreover, gender was significant in all final LMMs except for the model assessing naturalness. Female respondents usually gave higher scores than male respondents, while no differences were found with people that did not identify as either female or male (i.e., other gender) (see Table S4). 

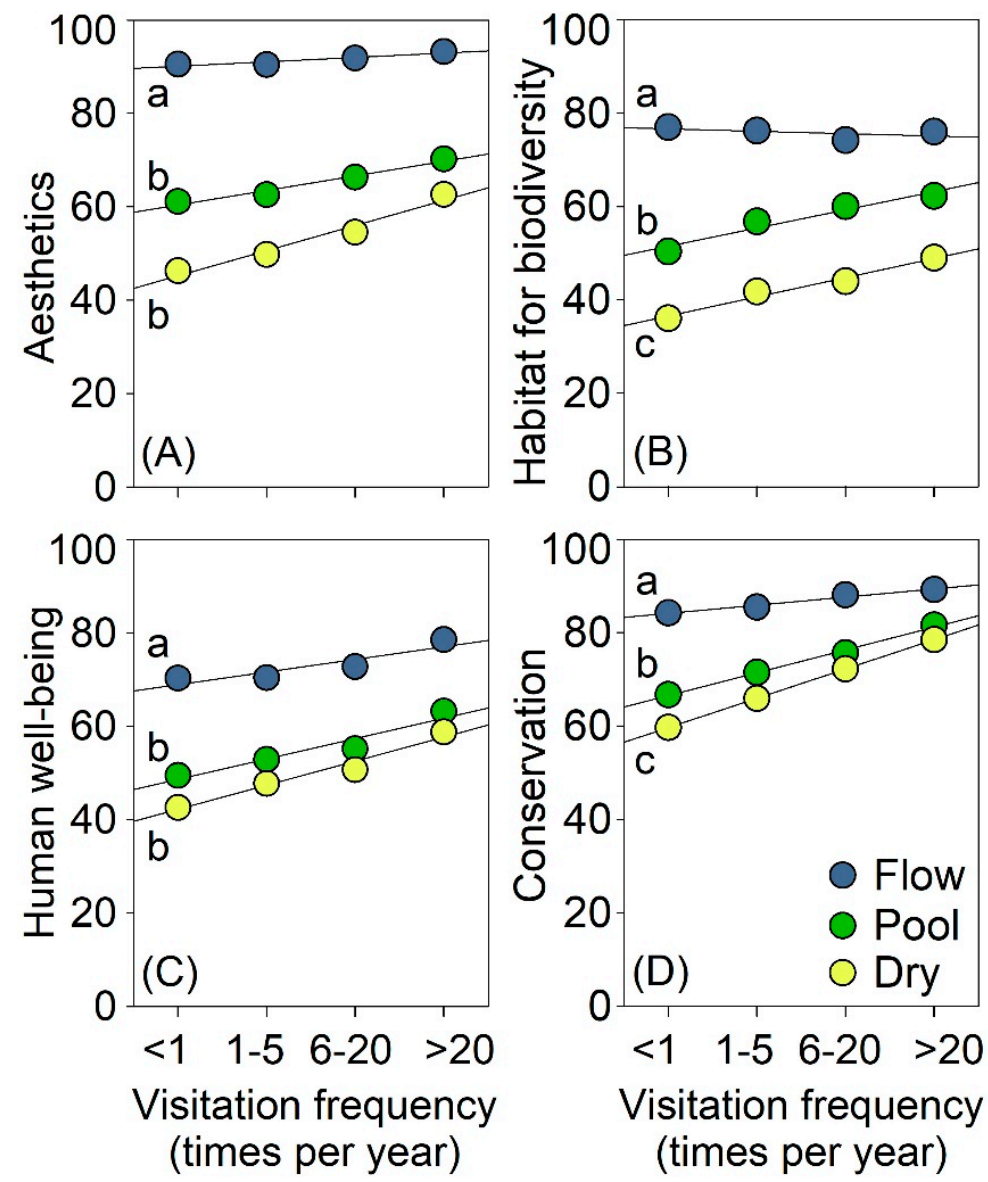

Figure 5. Effects of frequency of river visitation on the perception of images of flowing rivers (blue), isolated pools (green), and dry riverbeds (yellow) regarding aesthetics (A), habitat for biodiversity (B), human well-being (C), and conservation value (D). Four levels of visitation frequency were differentiated: less than once a year, from 1 to 5 times a year, from 6 to 20 times a year, and more than 20 times a year. Dots represent the mean values of respondents' rating using visual analog scales. Lines represent linear regressions to show tendencies. Different letters indicate statistically significant differences (Tukey's post-hoc tests, $p<0.05$ ). See Table S4 for full statistics.

\section{Discussion}

Our results showed that non-perennial rivers are considered less valuable than their perennial counterparts. Our survey to university students revealed that people perceive running rivers more positively than both isolated pools and dry riverbeds for the seven variables tested. Non-perennial rivers were considered less able to provide ecosystem services for humans and habitat for biodiversity and fish, less beautiful, more impacted by human activities, more in need of human intervention to improve them, and less worthy of conservation than perennial rivers. Moreover, isolated pools were perceived more positively than dry riverbeds for only three of the seven variables (i.e., habitat for biodiversity, habitat for fish, and conservation value). These results suggest it is not just the presence of water itself but rather flowing water that influences human perception of riverscapes, which builds on the previous research regarding the influence of water on landscape appreciation [15].

Students' perceptions of the ability of riverscapes to provide habitat for biodiversity and fish were highly correlated. This result suggests that students perceived total biodiversity in riverscapes as nearly equivalent to fish biodiversity and, most likely, to the availability of aquatic habitats within the river channel. However, rivers provide habitats to several semiaquatic and terrestrial species and, indeed, recent research has delved into the ecological functions that non-perennial rivers provide to terrestrial animals (e.g., movement corridors, migration stopovers, or breeding and nesting sites) [22]. 
For instance, a recent study about ground-dwelling arthropods concluded that dry channels can support a larger number of unique species, and more species overall, compared to perennial reaches [23]. Moreover, it has been recently documented that some fish species can survive in the hyporheic zone of non-perennial rivers in the absence of surface water (i.e., in the water-saturated interstitial spaces in the subsurface of dry riverbeds) [24,25]. In this vein, educating on the contribution of the dry phase of non-perennial rivers to biodiversity may positively influence peoples' perceptions toward these ecosystems. It is also worth noting that the weakest correlation was found between the perception of riverscapes' naturalness and the perception of their importance for human well-being. This may indicate that respondents considered the benefits humans obtain from rivers (i.e., ecosystem services) to be independent of a river's naturalness.

While the perception of perennial rivers was almost homogeneous among respondents, the perception of non-perennial watercourses was influenced by several factors. Educational history influenced students' perception of non-perennial streams. University training in ecology (i.e., courses on Ecology and Freshwater Ecology) improved students' perception of the naturalness and ecological importance of non-perennial rivers. Notably, previous research in this field [13] found that university training in ecology improved students' attitudes toward perennial rivers and flowing temporary rivers but had almost no effect on students' attitudes toward non-flowing temporary rivers. Our study builds on these previous findings by showing that university training in ecology can also positively influence students' perceptions of non-flowing rivers, including dry riverbeds. Moreover, respondents trained in Environmental Studies scored non-perennial rivers highly for human well-being and conservation value compared to those without that educational background. These findings suggest that formal training in human-nature relationships can be even more relevant than training in ecological science in growing public support to protect non-perennial rivers.

Knowledge is considered a necessary condition for developing positive environmental attitudes, although several other factors (e.g., sociodemographic aspects) may influence the development of environmental attitudes and behaviors [26-28]. In their literature review, Robelia and Murphy [29] stressed that knowledge is relevant in citizens' view of policy and a precursor to meaningful discourse about policy. In this vein, university education may be key for not only promoting more positive perceptions and attitudes toward non-perennial rivers but also for forming informed citizens able to have meaningful discourses about environmental policies that affect these ecosystems.

We also hypothesized that climate context would drive the social perception of non-perennial rivers. Studies testing cross-cultural differences on the perception of riverscapes are rare, but Le Lay [30] found that the perception of the value of large woody debris in rivers varied among geographical areas. People living in forested landscapes perceived wood within river channels more positively than people living in unforested regions, where in-channel wood is less common. With this in mind, one could expect that people living in arid and Mediterranean areas, where non-perennial rivers are the dominant river typology, value these ecosystems more highly than people living in wetter regions. However, we found the opposite. These results support the idea that water scarcity in arid and Mediterranean regions may negatively influence peoples' perceptions of non-perennial rivers. Another possibility is that many students may not be local; our survey did not ask about where the individual grew up or lived before, only their current location. It is possible that childhood experiences, including climate context, could be more important than current residence in determining how people perceive non-perennial waterways. Julian et al. [31] showed how time spent outside as a child may influence university students' perceptions, values, and uses of a river crossing the university campus. Research that delves more deeply into the influence of climate and socio-cultural contexts on the perception of non-perennial rivers and other ecosystems is needed, as well as those considering different developmental stages [31,32].

Over recent decades, people are less likely to have direct contact with nature in their everyday lives. This phenomenon can lead to an "extinction of experience" which negatively influences people's emotions, attitudes, and behaviors toward their environment [33]. We found that living close to a river, 
visiting rivers, and doing leisure activities (i.e., hiking, birdwatching) in the vicinity of rivers may have a positive impact on people's perception of non-perennial rivers. Our results suggest that public policies that try to reverse the "extinction of experience" phenomenon and encourage people to visit rivers and carry out leisure activities near them may improve their attitudes toward and interest in preserving non-perennial rivers.

In addition, the perception of riverscapes differed by age groups and gender. A recent literature review [34] concluded that age and gender can shape the social demands of aquatic ecosystems in a variety of ways. Because older students had, in general, more positive perceptions of non-perennial rivers than younger ones, our results support the idea that lifelong learning may be an important aspect of environmental literacy [29].

\section{Conclusions}

This study provides evidence that university students are largely unaware of the importance of non-perennial rivers and perceive these rivers more negatively than perennial ones, even in arid areas where non-perennial rivers are the norm. Educational history, frequency of river visitation, leisure activities, living close to a river, and other sociodemographic factors influenced students' perceptions of non-perennial rivers but did not change the general observed pattern. Our study centers human dimensions in the study of non-perennial rivers, which we consider necessary to guide conservation policies and help to counterbalance the current biophysical focus that characterizes almost all research on these systems $[35,36]$. We conclude that improving people's perceptions of non-perennial rivers is crucial if we are to grow public support to conserve these ecosystems and apply sustainable policies. This current challenge demands combined actions by researchers from diverse disciplines (e.g., ecology, conservation, environmental humanities) and professionals working from different perspectives, including policymakers and educators.

Supplementary Materials: The following are available online at http://www.mdpi.com/2071-1050/12/14/5782/s1, (1) Figure S1. Photographs used in the survey: running river (upper images), isolated pools (middle images), and dry riverbeds (lower images). Photographs by MTB (top-left, middle-center, middle-right, bottom-left, bottom-right), PR-L (middle-left, top-center), Raphael Mazor (bottom-center), and Lucy Andrews (top-right). Table S1. Description of sociodemographic characteristics of survey respondents, used as fixed effects in full LMMs. Table S2. Spearman correlations' coefficients (Spearman's rho) between the seven characteristics evaluated: aesthetics, naturalness, habitat for biodiversity, habitat for fish, need of improvement, human well-being, and worthy of conservation. Table S3. Variance explained by the LMMs $\left(R^{2} m=\right.$ marginal $R^{2} ; R^{2} c=$ conditional $\left.R^{2}\right)$ and percentage of the explained variance (PctExp) by flow status. Table S4. Statistics of the LMMs' retained fixed effects and summary of Tukey's post-hoc tests. When fixed effects had a statistically significant interaction with "flow status", only the Tukey's post-hoc test results for the interaction are reported. Significance level set at $\alpha<0.05$ for all tests. A = running rivers; B = isolated pools, C = dry riverbeds, n.s. = no statistically significant (reported when post-hoc tests show no significant pairwise differences). See Table S1 for abbreviations. (2) Image-based online survey to measure people's perception of riverscapes.

Author Contributions: Conceptualization, P.R.-L.; methodology, P.R.-L., C.W.-E., M.T.B. and S.M.C.; validation, P.R.-L., C.W.-E., M.T.B. and S.M.C.; formal analysis, P.R.-L.; investigation, P.R.-L., C.W.-E., M.T.B. and S.M.C.; data curation, P.R.-L.; writing—original draft preparation, P.R.-L.; writing—review and editing, P.R.-L., C.W.-E., M.T.B. and S.M.C.; visualization, P.R.-L.; supervision, S.M.C.; project administration, P.R.-L. All authors have read and agreed to the published version of the manuscript.

Funding: This research has no external funding.

Acknowledgments: We thank all survey respondents and all those who helped to disseminate the survey. We are grateful to Raphael Mazor and Lucy Andrews for providing photographs of rivers. PR-L was supported by a Ramón Areces Foundation Postdoctoral Scholarship and by a Margalida Comas postdoctoral contract (PD/031/2018) funded by the Government of the Balearic Islands and the European Social Fund. This study was approved by the Committee for Protection of Human Subjects of the University of California at Berkeley that serves as an Institutional Review Board (IRB) (protocol number \#2017-09-10299). The University of Arizona's IRB and the University of Washington Human Subjects Division agreed to rely on the review, approval, and continuing oversight of the UC Berkeley's IRB to the terms of the Institutional Review Board Authorization Agreement (University of Arizona's protocol number \#1803351040; University of Washington's protocol number \# STUDY00004368). We thank the Editor and the two reviewers for their help to improve this article.

Conflicts of Interest: The authors declare no conflict of interest. 


\section{References}

1. Carlisle, D.M.; Wolock, D.M.; Meador, M.R. Alteration of streamflow magnitudes and potential ecological consequences: A multiregional assessment. Front. Ecol. Environ. 2011, 9, 264-270. [CrossRef]

2. Datry, T.; Larned, S.T.; Tockner, K. Intermittent rivers: A challenge for freshwater ecology. Bioscience 2014, 64, 229-235. [CrossRef]

3. Nadeau, T.L.; Rains, M.C. Hydrological connectivity between headwater streams and downstream waters: How science can inform policy. J. Am. Water Resour. Assoc. 2007, 43, 118-133. [CrossRef]

4. Datry, T.; Foulquier, A.; Corti, R.; Von Schiller, D.; Tockner, K.; Mendoza-Lera, C.; Clément, J.C.; Gessner, M.O.; Moleón, M.; Stubbington, R.; et al. A global analysis of terrestrial plant litter dynamics in non-perennial waterways. Nat. Geosci. 2018, 11, 497-503. [CrossRef]

5. von Schiller, D.; Datry, T.; Corti, R.; Foulquier, A.; Tockner, K.; Marcé, R.; García-Baquero, G.; Odriozola, I.; Obrador, B.; Elosegi, A.; et al. Sediment Respiration Pulses in Intermittent Rivers and Ephemeral Streams. Global Biogeochem. Cycles 2019, 33, 1251-1263. [CrossRef]

6. Marshall, J.C.; Acuña, V.; Allen, D.C.; Bonada, N.; Boulton, A.J.; Carlson, S.M.; Dahm, C.N.; Datry, T.; Leigh, C.; Negus, P.; et al. Protecting US river health by maintaining the legal status of their temporary waterways. Science 2018, 361, 856-857.

7. Fritz, K.M.; Cid, N.; Autrey, B. Governance, legislation, and protection of intermittent rivers and ephemeral streams. In Intermittent Rivers and Ephemeral Streams: Ecology and Management; Datry, T., Bonada, N., Boulton, A.J., Eds.; Elsevier B.V.: Amsterdam, The Netherlands, 2017; pp. 477-507, ISBN 9780128039045.

8. Acuña, V.; Datry, T.; Marshall, J.C.; Barceló, D.; Dahm, C.N.; Ginebreda, A.; McGregor, G.; Sabater, S.; Tockner, K.; Palmer, M.A. Why should we care about temporary waterways? Science 2014, 343, 1080-1081. [CrossRef]

9. Steward, A.L.; von Schiller, D.; Tockner, K.; Marshall, J.C.; Bunn, S.E. When the river runs dry: Human and ecological values of dry riverbeds. Front. Ecol. Environ. 2012, 10, 202-209. [CrossRef]

10. Boulton, A.J. Conservation of ephemeral streams and their ecosystem services: What are we missing? Aquat. Conserv. Mar. Freshw. Ecosyst. 2014, 24, 733-738. [CrossRef]

11. Datry, T.; Boulton, A.J.; Bonada, N.; Fritz, K.M.; Leigh, C.; Sauquet, E.; Tockner, K.; Hugueny, B.; Dahm, C.N. Flow intermittence and ecosystem services in rivers of the Anthropocene. J. Appl. Ecol. 2018, 55, 353-364. [CrossRef]

12. Armstrong, A.; Stedman, R.C.; Bishop, J.A.; Sullivan, P.J. What's a stream without water? Disproportionality in headwater regions impacting water quality. Environ. Manag. 2012, 50, 849-860. [CrossRef] [PubMed]

13. Leigh, C.; Boersma, K.S.; Galatowitsch, M.L.; Milner, V.S.; Stubbington, R. Are all rivers equal? The role of education in attitudes towards temporary and perennial rivers. People Nat. 2019, 1, 181-190. [CrossRef]

14. Gonzalez, C.; Clemente, A.; Nielsen, K.A.; Branquinho, C. Human-Nature Relationship in Mediterranean Streams: Integrating. Ecol. Soc. 2009, 14, 25. [CrossRef]

15. Herzog, T.R. A cognitive analysis of preference for waterscapes. J. Environ. Psychol. 1985, 5, $225-241$. [CrossRef]

16. Couper, M.P.; Tourangeau, R.; Conrad, F.G.; Singer, E. Evaluating the effectiveness of visual analog scales. Soc. Sci. Comput. Rev. 2006, 24, 227-245. [CrossRef]

17. Liu, M.; Conrad, F.G. An experiment testing six formats of 101-point rating scales. Comput. Human Behav. 2016, 55, 364-371. [CrossRef]

18. Groves, R.M.; Fowler, J.R.; Couper, M.P.; Lepkowski, J.M.; Singer, E.; Tourangeau, R. Survey Methodology; John Wiley \& Sons: Hoboken, NJ, USA, 2011.

19. Zuur, A.F.; Ieno, E.N.; Walker, N.J.; Saveliev, A.A.; Smith, G.M. Mixed Effects Models and Extensions in Ecology with R; Springer: New York, NY, USA, 2009; ISBN 9780387874579.

20. Fox, J.; Monette, G. Generalized collinearity diagnostics. J. Am. Stat. Assoc. 1992, 87, 178-183. [CrossRef]

21. Nakagawa, S.; Schielzeth, H. A general and simple method for obtaining R2 from generalized linear mixed-effects models. Methods Ecol. Evol. 2013, 4, 133-142. [CrossRef]

22. Sánchez-Montoya, M.M.; Moleón, M.; Sánchez-Zapata, J.A.; Escoriza, D. The biota of intermittent and ephemeral rivers: Amphibians; reptiles; birds; and mammals. In Intermittent Rivers and Ephemeral Streams: Ecology and Management; Datry, T., Bonada, N., Boulton, A.J., Eds.; Elsevier B.V.: Amsterdam, The Netherlands, 2017; pp. 299-322. 
23. Sánchez-Montoya, M.M.; Tockner, K.; von Schiller, D.; Miñano, J.; Catarineu, C.; Lencina, J.L.; Barberá, G.G.; Ruhi, A. Dynamics of ground-dwelling arthropod metacommunities in intermittent streams: The key role of dry riverbeds. Biol. Conserv. 2020, 241, 108328. [CrossRef]

24. Kawanishi, R.; Inoue, M.; Dohi, R.; Fujii, A.; Miyake, Y. The role of the hyporheic zone for a benthic fish in an intermittent river: A refuge, not a graveyard. Aquat. Sci. 2013, 75, 425-431. [CrossRef]

25. Rodríguez-Lozano, P.; Leidy, R.A.; Carlson, S.M. Brook lamprey survival in the dry riverbed of an intermittent stream. J. Arid Environ. 2019, 166, 83-85. [CrossRef]

26. Barata, R.; Castro, P.; Martins-Loução, M.A. How to promote conservation behaviours: The combined role of environmental education and commitment. Environ. Educ. Res. 2017, 23, 1322-1334. [CrossRef]

27. Kollmuss, A.; Agyeman, J. Mind the Gap: Why do people act environmentally and what are the barriers to pro-environmental behavior? Environ. Educ. Res. 2002, 8, 239-260. [CrossRef]

28. Bamberg, S.; Möser, G. Twenty years after Hines, Hungerford, and Tomera: A new meta-analysis of psycho-social determinants of pro-environmental behaviour. J. Environ. Psychol. 2007, 27, 14-25. [CrossRef]

29. Robelia, B.; Murphy, T. What do people know about key environmental issues? A review of environmental knowledge surveys. Environ. Educ. Res. 2012, 18, 299-321. [CrossRef]

30. Le Lay, Y.-F.; Piégay, H.; Gregory, K.; Chin, A.; Dolédec, S.; Elosegi, A.; Mutz, M.; Wyzga, B.; Zawiejska, J. Variations in cross-cultural perception of riverscapes in relation to in-channel wood. Trans. Inst. Br. Geogr. 2008, 33, 268-287. [CrossRef]

31. Julian, J.P.; Daly, G.S.; Weaver, R.C. University students' social demand of a blue space and the influence of life experiences. Sustainability 2018, 10, 3178. [CrossRef]

32. Liefländer, A.K. Effectiveness of environmental education on water: Connectedness to nature, environmental attitudes and environmental knowledge. Environ. Educ. Res. 2015, 21, 145-146. [CrossRef]

33. Soga, M.; Gaston, K.J. Extinction of experience: The loss of human-nature interactions. Front. Ecol. Environ. 2016, 14, 94-101. [CrossRef]

34. Flotemersch, J.E.; Shattuck, S.M.; Aho, K.B.; Cox, C.E.; Cairns, M.R. Factors influencing social demands of aquatic ecosystems. Ecol. Soc. 2019, 24. [CrossRef]

35. Castillo, A.; Bullen-Aguiar, A.A.; Peña-Mondragón, J.L.; Gutiérrez-Serrano, N.G. The social component of social-ecological research: Moving from the periphery to the center. Ecol. Soc. 2020, 25. [CrossRef]

36. Olsson, L.; Ness, B. Better balancing the social and natural dimensions in sustainability research. Ecol. Soc. 2019, 24. [CrossRef] 